\title{
ANESTHETIC MANAGEIMENT OF A CASE OF TAKAYASU'S ARTERITIS POSTED FOR AUTORENAL TRANSPLANTATION
}

KEY WORDS: Takayasu's arteritis Renal hypertension Renalautotransplantation General anesthesia

\section{Dr. Neelima J*}

Dr. Rathva

Darshikaben

Maheshbhai
Postgraduate [MD Anaesthesiology] Department of Anaesthesiology, IKDRC, BJMC, Civil hospital Ahmedabad. *Corresponding Author

Postgraduate [MD Anaesthesiology] Department of Anaesthesiology, IKDRC, BJMC, Civil hospital Ahmedabad.

Takayasu's arteritis is a rare, chronic progressive pan endarteritis involving the aorta and its main branches. It is one of the most important causes of renovascular hypertension. The best treatment is autorenal transplantation. Though it is a safe procedure to perform, a stable perioperative haemodynamics with adequate renal perfusion pressure is required for a successful outcome.

\section{INTRODUCTION}

Takayasu's arteritis is a chronic, progressive, autoimmune idiopathic, large-vessel vasculitis that usually affects young adults. The diffuse nature of this vasculitis can affect multipleorgan systems to varying degrees. It is a single most important cause of renovascular hypertension. Anaesthetizing a child with takayasu's arteritis for autorenal transplantation is a challenge as it is complicated by severe uncontrolled hypertension, endorgan dysfunction, stenosis of major blood vessels affecting regional circulation. Takayasu's arteritis is characterized by a focal stenosis process involving the aorta and the proximal segment of its major branches. We present the anaesthetic management of a child with Takayasu's arteritis and severe hypertension refractory to medical treatment requiring auto renal transplantation.

\section{CASE REPORT}

A 13yr old male child, a k/c/o takayasu's arteritis with malignant HTN, CKD since 1 month on MHD 2/wk, B/L renal artery stenosis with Right subclavian artery occlusion posted for Autorenal transplantation.

On Examination,

weight: $27 \mathrm{~kg}$, height- $130 \mathrm{~cm}$,

Pulse-150/MIN, BP-140/90 mm hg, on air SP02-100\%, pallor,$++ \mathrm{B} / \mathrm{L}$ Pedal edema+nt

lRS - B/L creps + nt. CVS-S1,S2+nt

\section{Drug Histroy:}

T. ARKAMIN TDS IT.NFR BD IT.PRAZOSIN BD I

T.SOBOSIS BD

\section{Pre-op Investigation:}

$\mathrm{Hb}-8.2, \mathrm{TLC}-6770, \mathrm{PC}-692000$ RBS- 94 ,

S.CR-4.32,NA - 132.9, K-3.57,PT-39.6, INR-3.57

APTT-3.57, CXR - cardiomegaly, ECG -LVH,

Tinversion in V3,V4,V5,V6.2DECHO-EF-55\%,

TR GMAX-34 MmHg, Global LV, Hypokinesia, Dilated LV size, Mild TR with Mild PAH,Thin rim of pericardia! effusion.

\section{FUNDUS EXAMINATION - Normal}

- Cardiologist reference was done fitness given with high risk of perioperative events.

- Written and informed high-risk consent taken.

- Patient kept NBM.

- Morning dose of anti-hypertensive drugs taken.

\section{INTRA OPERATIVE ANAESTHETIC MANAGEMENT}

CHOICE OF ANESTHESIA: Balanced general anesthesia.

PREMEDICATION: lnj. glycopyrrolate

$0.2 \mathrm{mg}$, inj. fentanyl 60 microgram, inj. ondensatrone $3 \mathrm{mg}$ iv

|www.worldwidejournals.com given. INDUCTION with inj. thiopentole $160 \mathrm{mg}$, inj. scoline 50 mg. INTUBATION done rapidly with PETT NO 6 cuffed tube inserted, B/L AE equal.

Maintenance with isoflurane, o2,inj atracurium,and inj NTG infusion. Left radial artery opposite to the site of arteriovenous fistula was cannulated and invasive EV1000 monitor attached to evaluate $\mathrm{co}, \mathrm{sv}, \mathrm{svv}$ to guide iv fluids.

- intraoperatively continuous heparin infusion was given as this patient was hypercoagulable. intraoperative blood loss was replaced by 2 units pcv and gelofusion.

- Normocarbia was maintained to preserve cerebral perfusion.

- A good perfusion pressure of the transplanted kidney was ensured by maintaining systolic bp of $130 \mathrm{~mm}$ hg, cvp of 12-14 mm of $\mathrm{Hg}$, mannitol was transfused before clamp release.

- Surgery and anaesthesia were uneventful and on table good urine output was established. After transplant patient was extubated and shift to ccu for monitoring.

\section{DISCUSSION}

- Anaesthetising such a child for auto renal transplantation is a challenge as it is complicated by severe uncontrolled hypertension, end-organ dysfunction.

- Regional analgesia with epidural was not initiated in our patient as the risk of hypotension and haemodynamic instability can also result in reduced graft function.

- CVP of 12-14 mmHg is recommended to maintain optimal intravascular volume.

- Successful outcome depends on preoperative optimisation, intra operative maintenance of stable hemodynamics and invasive monitoring during perioperative period. Anesthetic concerns are related to severe uncontrolled hypertension, end-organ dysfunction, stenosis, or aneurysms of major blood vessels affecting regional circulation and difficulties in monitoring

BP(4).

Principal anesthetic implications of the procedure are,

- Maintenance of the renal perfusion pressure to ensure optimal graft perfusion and function.

- Maintaining haemodynamics (avoiding sudden hypotension and hypertension) to prevent possible cerebrovascular and cardiovascular crisis.

- Maintaining adequate intravascular volume.

- Maintaining Normothermia.

- Management of intra and postoperative analgesia.

- Epidural analgesia offers the advantages of the blockade of peripheral Sympathetic 
nervous system. At low concentrations it provides analgesia and helps in maintaining stable haemodynamics perioperatively.

\section{CONCLUSION}

Administration of GA in Takayasu's arteritis for major blood vascular procedure is challenging and need special attention to pre-operative optimization of the patient, peri-operative management of cvs and maintenance of cerebral and other organ perfusion with maintenance of acid base status is also important.

\section{REFERENCES}

1. Rozwadowski MA, Downing SW. Anaesthetic management for nephrectomy in a child with Takayasu's arteritis and severe renovascular hypertension. $\mathrm{S}$ Afr Med J. 1985;67:898-900.

2. Wang PK, Luo BH, Chen A, YiLee, Lai HY. Anesthetic considerations in Takayasu's arteritis-Acase report. Tzu Chi MedJ.2006;18:53-56.

3. Kathirvel S, Chavan S, Arya VK, Rehman I, Babu V, Malhotra N, et al. Anesthetic management of patients with Takayasu's arteritis: A Case Series and Review. Anesth Analg. 2001;93:60-5.

4. Bhalla A, D'Cruz S, Lehi SS, Singh R. Renovascular hypertension-Its evaluation and management.JIACM. 2003;4:139-46.

5. Ishikawa K, Matsuura S. Occlusive thromboaortopathy (Takayasu's disease) and pregnancy: clinical course and management of 33 pregnancies and deliveries. Am J Cardiel. 1982;50:1293-300.

6. Wiebers DO. lschemic cerebrovascular complications of pregnancy. Arch Neural. 1985;42:1106-13.

7. Sahajananda H, Jyothi, Punithavathy Renal transplantation with and without epidural analgesia-A review of 6 years of experience. Indian J Anaesth. 2006;50:187-192

8. Reyle-Hahn M, Max M, Kuhlen R, Rossaint R. Preoperative and postoperative anaesthesiological management in patients undergoing liver or kidney transplantation. Acta Anaesthesiol Scand Suppl. 1997;41:80-84. 